\title{
Experimental Research on Desliming and Separation of Gold Mine Tailings
}

\author{
Peikun LIU ${ }^{1,2}$, Qingzhi XU' ${ }^{2}$, Xinghua YANG ${ }^{2}$, YueKan ZHANG ${ }^{2}$ \\ ${ }^{1 .}$ Key Laboratory of Gold Mineralization processes and Resource Utilization Subordinated to the Ministry of \\ Land and Resources, Key Laboratory of Metallogenic Geological Process and Resources Utilization in \\ Shandong Province, China \\ ${ }^{2}$ Shandong University of Science and Technology, College of Mechanical \& Electric Engineering, Qingdao, \\ China
}

\begin{abstract}
The large amount of fine slime in the tailing often lead to low separation and recycling efficiency during the treatment of gold mine tailing. In order to solve the problem, a new type of multi-conical hydrocyclone is proposed as the desliming and separation equipment for a certain gold mine tailing whose gold grade is $0.45 \mathrm{~g} / \mathrm{t}$ and fine grain content of $-15 \mu \mathrm{m}$ size is $70 \%$. The experimental results show that the fine grain content of $-15 \mu \mathrm{m}$ size in the overflow can reach $90 \%$ after classification by the hydrocyclone, and the gold grade in the underflow reach $0.75 \mathrm{~g} / \mathrm{t} \sim 0.8 \mathrm{~g} / \mathrm{t}$. It is concluded that by use of the multi-conical hydrocyclone, the fine slime can be removed from the mine tailing and the gold component can be enriched effectively.
\end{abstract}

KEYWORD: Gold Mine Tailing; Desliming; Separation; Hydrocyclone

\section{INSTRUCTIONS}

There are small amount of gold in the gold tailing which are still valuable. In recent years, many dressing mill begin to emphasize the treatment of gold tailing in order to recycle the valuable components. And the hydrocyclone is always to used to recycle valuable component from tailings (M.Fall, 2005). Hydrocyclone can classify particles according to the size and separate them by density, therefore, it has been widely used for the treatment of tailings(Ozgen. S,2012). Especially, the short cone cyclone (cone angle is $120^{\circ}$ ) is used as enrichment equipment because it can obtain products with high enrichment ratio.

However, the large amount of fine slime in the gold tailing leads to a low separation efficiency and recovery rate when it is classified by the hydrocyclone. In order to solve the problem, a new type of multi-conical hydrocyclone is proposed and its prominent characteristic is that, the slurry tangential velocity is firstly increased in the upper wide angle part, then the residence time of the slurry is extended in the lower small angle part. Therefore, it is beneficial to complete the refined classification and very suitable for the desliming and separation of gold tailings. In this paper, a series of experiments are conducted with different structure and operating parameters to verify the property of the multiconical hydrocyclone .

\section{TAILING PROPERTIES}

Sieve the flotation gold tailing with five different specification screen and obtain the yield of five different particle samples. Determine the gold grade and the distribution rate in each sample. The results are listed in table 1.

Table 1. Particle size distribution and phase distribution.

\begin{tabular}{|c|c|c|c|}
\hline $\begin{array}{c}\text { Particle size, } \\
\mu \mathrm{m}\end{array}$ & $\begin{array}{c}\text { Particle } \\
\text { yield, } \%\end{array}$ & $\begin{array}{c}\text { Gold grade, } \\
\text { g/t }\end{array}$ & $\begin{array}{c}\text { Distribution } \\
\text { rate, } \%\end{array}$ \\
\hline+100 & 0.30 & 1.08 & 0.72 \\
\hline$-100+74$ & 1.38 & 1.09 & 3.36 \\
\hline$-74+38$ & 21.52 & 0.69 & 33.12 \\
\hline$-38+30$ & 7.71 & 0.53 & 9.07 \\
\hline$-30+15$ & 0.08 & 0.35 & 0.06 \\
\hline-15 & 69.01 & 0.35 & 53.67 \\
\hline
\end{tabular}

From table 1, gold mine tailing particle size are mainly distributed in $0 \sim 100 \mu \mathrm{m}$ and most of them are fine particles. The particle yield of $-15 \mu \mathrm{m}$, $38 \mu \mathrm{m},-74 \mu \mathrm{m}$ is $69.01 \%, 76.80 \%$ and $98.32 \%$ respectively. With the decrease of the particle size, the gold reduces gradually. Although the gold grade of $-15 \mu \mathrm{m}$ particles in the gold tailing is only $0.35 \mathrm{~g} / \mathrm{t}$, it is should not be ignored that the content of $-15 \mu \mathrm{m}$ particles reaches $69.01 \%$, as a result the overall distribution rate of gold in $-15 \mu \mathrm{m}$ particles is $53.67 \%$, which occupies nearly half of the total gold content in the tailing. Therefore, the removal of fine 
slime in $-15 \mu \mathrm{m}$ particles is essential for the enrichment of gold.

\section{MULTI-CONICAL HYDROCYCLONE}

\subsection{The separation mechanism of hydrocyclone}

The hydrocyclone is an effective equipment for accelerating the settling velocity and strengthening the separation process by use of centrifugal force field. If materials with different particle size and same density are separated in the hydrocyclone, the materials whose particle size is less than the separation size goes into the overflow and the materials whose particle size is greater than the separation size goes into the underflow(Da Li,2013). Furthermore, if the material density is also different, then all the materials will have the same settling velocity, and a part of denser fine material particles will enters into the underflow. Hence, the separation of materials with different density can be completed.

Many researchers have found that the tangential velocity of fluid is the main factor of the separation(D. O. Silva,2012). On the basis of this point, the first conical part of the multi-conical hydrocyclone is designed with a large cone angle, which can improve the tangential velocity of pulp and let the high density large particles subside rapidly and enters into the outside helical flow. The second conical part is characterized by a small cone angle, which can increase the separation space, extend the residence time of materials, improve the separating accuracy and reduce the lower limit of separation. Finally, considering a part of low density fine particles following the water distribution will enter into the underflow, a larger cone angle is designed for the third part because it can further separate high-concentration material and reduce the low density fine particles in the underflow product effectively.

From the above, the coarse particles and a part of the fine particles containing the denser gold component sink into the underflow, while the low grade fine slime goes into overflow. Such separation process can realize the enrichment of gold and increase the recovery rate effectively.

\subsection{Structure design of multi-conical hydrocyclone}

A new type of multi-conical hydrocyclone is proposed according to the particle size distribution of the tailing and the requirement of removing $15 \mu \mathrm{m}$ size particles. Compared with the traditional hydrocyclone, it has a combination of three different conical section, by use of which the residence time of particles can be extended and the separation efficiency and precision can be improved. Its structure is shown as figure 1 and the structure parameters are shown in table 2 .
Table 2. structure parameters of the multi-conical hydrocyclone

\begin{tabular}{|c|c|c|c|c|c|c|}
\hline $\begin{array}{c}\text { structure } \\
\text { parameters }\end{array}$ & $\begin{array}{c}\mathrm{d}_{\mathrm{c}} / \\
\mathrm{mm}\end{array}$ & $\begin{array}{c}\mathrm{d}_{\mathrm{i}} / \\
\mathrm{mm}\end{array}$ & $\begin{array}{c}\mathrm{d}_{\mathrm{o}} / \\
\mathrm{mm}\end{array}$ & $\begin{array}{c}\mathrm{d}_{\mathrm{s}} / \\
\mathrm{mm}\end{array}$ & $\mathrm{d}_{\mathrm{s}} / \mathrm{d}_{\mathrm{o}}$ & $\begin{array}{c}\mathrm{L} / \\
\mathrm{mm}\end{array}$ \\
\hline value & 150 & 40 & 45 & 18 & $0.4 / 0.44 / 0.48$ & 100 \\
\hline
\end{tabular}

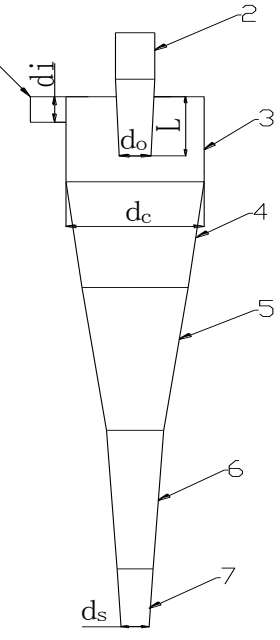

Figure 1. multi-conical hydrocyclone

1-feed pipe; 2-overflow pipe; 3-swirl chamber; 4-the first cone part; 5-the second cone part; 6-the third cone part; 7-underflow

\subsection{Experiment device}

The experimental platform is mainly composed of agitation tank, piping system, slurry pump, pressure gauge and the hydrocyclone, as shown in figure 2 . In the experiments, the tailing slurry is mixed equably in the agitation tank, then it is transported into the hycyclone through the slurry pump. After the desliming separation treatment, both the fine particles from the overflow pipe and coarse particles from the underflow pipe flow back to the agitation tank and form a closed cycle system. Sampling tubes are installed on the entrance, overflow and underflow for further analysis.

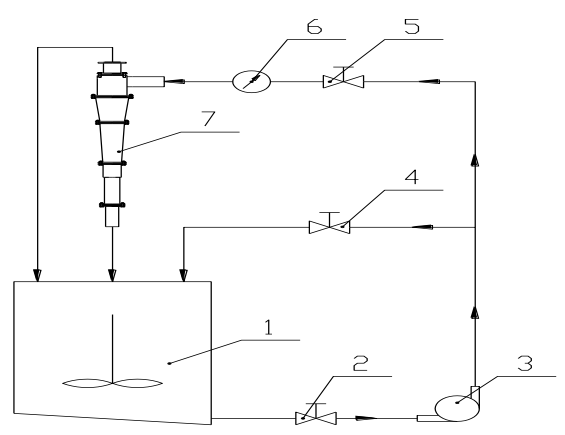

Figure 2. Experimental platform

1-agitation tank; 2-control valve; 3-slurry pump; 4-return valve; 5-flow control valve; 6-pressure gauge; 7-multi-conical hydrocyclone

\section{EXPERIMENT RESULTS ANALYSIS}

In order to test the separation effect of the multiconical hydrocyclone, a series of experiments have 
been carried out on the condition that $\mathrm{d}_{\mathrm{s}} / \mathrm{d}_{\mathrm{o}}$ is 0.4 , $0.44,0.48$ and the inlet pressure is $0.10 \mathrm{MPa}$ and $0.15 \mathrm{MPa}$ respectively. The drying-weighing method is used to get the concentration of each sample. Sieve each sample and obtain its size composition, then measure its gold grade.

\subsection{Overflow and underflow products analysis}

The size composition and gold grade of the feed, overflow and underflow products are shown in table 3 , table 4. From the experiment results it can be seen that, the multi-conical hydrocyclone shows good classification effect for dealing with gold mine tailing. The content of $-15 \mu \mathrm{m}$ particles reaches about $90 \%$ in the overflow product and $9 \%$ 18\% in the underflow product. Obviously, most fine slime particles of this size can be removed effectively. In addition, from the table 3 and the table 4 , the gold grade of overflow reduces to $0.2 \sim 0.3 \mathrm{~g} / \mathrm{t}$ while in the underflow it increases to $0.74 \sim 0.83 \mathrm{~g} / \mathrm{t}$, showing that the gold grade is enriched effectively.

\subsection{Newton classification efficiency, the solid yield} and the gold recovery rate of the underflow

According to the experiment data, the newton classification efficiency of different particle size, the solid yield and the recovery rate of the underflow product are analyzed and shown as figure 3 6.

Figure 3 and 4 illustrate the newton classification efficiency of $-38 \mu \mathrm{m},-30 \mu \mathrm{m},-15 \mu \mathrm{m}$ particles at $0.1 \mathrm{MPa}$ and $0.15 \mathrm{MPa}$ pressure respectively. From figure 3 , with the increase of the ratio of underflow to overflow pipe diameter, the newton classification efficiency of $-38 \mu \mathrm{m}$ and $-30 \mu \mathrm{m}$ size particles reduce gradually, but that of $-15 \mu \mathrm{m}$ size particles increases firstly and then decreases. It is because when $\mathrm{d}_{\mathrm{s}} / \mathrm{d}_{\mathrm{o}}$ is low, the overflow product will be mixed up with many coarse particles, reversely, when it increases the underflow product will be mixed with fine particle easily. Compare Figure 3 and figure 4, it can be seen that the pressure change has little effect on the classification efficiency of each size particle. In sum, when $d_{s} / d_{o}$ is 0.44 and the feed pressure is $0.15 \mathrm{MPa}$, the newton classification efficiency of $15 \mu \mathrm{m}$ particles reaches the maximum of $82 \%$, showing the best classification effect.

Table 3. Experimental result of overflow and underflow products (0.10MPa)

\begin{tabular}{|c|c|c|c|c|c|c|}
\hline ds/do & sample & concentration(\%) & $\begin{array}{c}\text { The content of }-38 \mu \mathrm{m} \\
\text { size particle }(\%)\end{array}$ & $\begin{array}{c}\text { The content of }-30 \mu \mathrm{m} \\
\text { size particle }(\%)\end{array}$ & $\begin{array}{c}\text { The content of }-15 \mu \mathrm{m} \\
\text { size particle }(\%)\end{array}$ & $\begin{array}{c}\text { Gold } \\
\text { grade }(\mathrm{g} / \mathrm{t})\end{array}$ \\
\hline \multirow{3}{*}{0.4} & ore feeding & 21.45 & 77.96 & 70.28 & 69.59 & 0.44 \\
\hline & overflow & 16.12 & 98.51 & 94.44 & 87.15 & 0.31 \\
\hline & underflow & 61.72 & 30.44 & 20.85 & 9.64 & 0.79 \\
\hline \multirow{3}{*}{0.44} & ore feeding & 21.97 & 77.76 & 68.91 & 63.06 & 0.46 \\
\hline & overflow & 15.31 & 99.28 & 96.57 & 92.84 & 0.26 \\
\hline & underflow & 57.91 & 40.39 & 28.04 & 11.77 & 0.74 \\
\hline \multirow{3}{*}{0.48} & ore feeding & 22.18 & 78.74 & 70.88 & 68.20 & 0.45 \\
\hline & overflow & 14.85 & 99.73 & 98.27 & 93.02 & 0.22 \\
\hline & underflow & 52.63 & 46.31 & 33.68 & 14.63 & 0.76 \\
\hline
\end{tabular}

Table 4. Experimental result of overflow and underflow products $(0.15 \mathrm{MPa})$

\begin{tabular}{|c|c|c|c|c|c|c|}
\hline ds/do & sample & Concentration $(\%)$ & $\begin{array}{c}\text { The content of }-38 \mu \mathrm{m} \\
\text { size particle }(\%)\end{array}$ & $\begin{array}{c}\text { The content of }-30 \mu \mathrm{m} \\
\text { size particle }(\%)\end{array}$ & $\begin{array}{c}\text { The content of }-15 \mu \mathrm{m} \\
\text { size particle }(\%)\end{array}$ & $\begin{array}{c}\text { Gold } \\
\operatorname{grade}(\mathrm{g} / \mathrm{t})\end{array}$ \\
\hline \multirow{3}{*}{0.4} & ore feeding & 21.45 & 77.96 & 70.28 & 69.59 & 0.44 \\
\hline & overflow & 15.94 & 99.13 & 95.87 & 89.07 & 0.28 \\
\hline & underflow & 64.20 & 30.56 & 20.71 & 9.03 & 0.83 \\
\hline \multirow{3}{*}{0.44} & ore feeding & 21.97 & 77.76 & 68.91 & 63.06 & 0.46 \\
\hline & overflow & 15.10 & 99.64 & 97.68 & 93.32 & 0.25 \\
\hline & underflow & 63.09 & 35.00 & 23.63 & 9.83 & 0.75 \\
\hline \multirow{3}{*}{0.48} & ore feeding & 22.18 & 78.74 & 70.88 & 68.20 & 0.45 \\
\hline & overflow & 14.76 & 99.91 & 98.93 & 94.79 & 0.25 \\
\hline & underflow & 58.33 & 45.41 & 31.95 & 17.84 & 0.79 \\
\hline
\end{tabular}




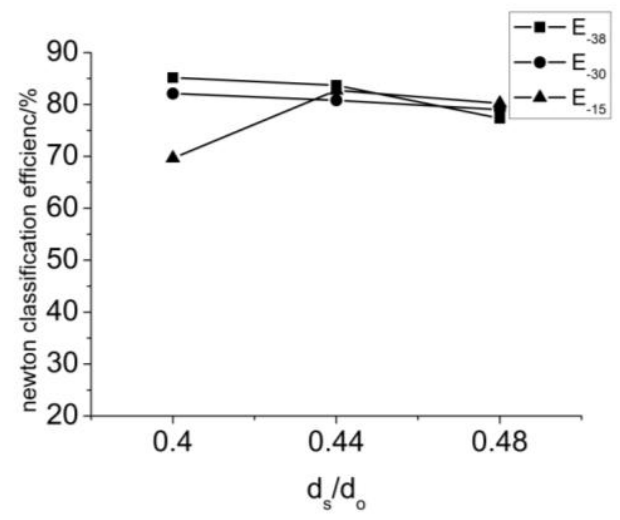

Figure 3.the newton classification efficiency $(0.1 \mathrm{MPa})$

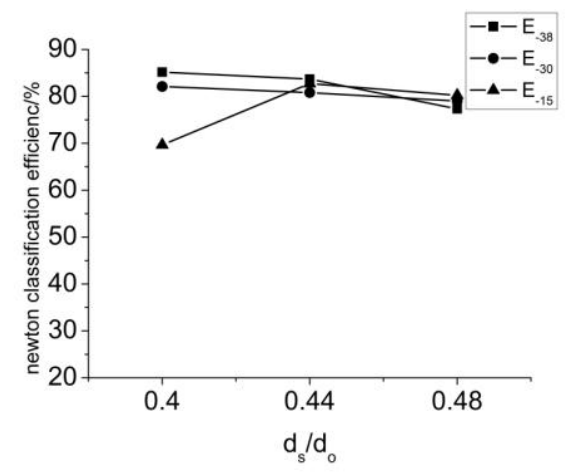

Figure 4. the newton classification efficiency $(0.15 \mathrm{MPa})$

The yield and gold recovery rate of the underflow are shown in figure 5 and 6 . It can be seen that with the increase of $d_{s} / d_{o}$, the yield increases significantly. For feed pressure $0.1 \mathrm{MPa}$ and $0.15 \mathrm{MPa}$, it shows little difference. This is because that, according to the calculation formula, the the separation size has direct ratio to the fourth root of pressure. Therefore, the pressure variation has little effect on it, From figure 6, with the increase of $d_{s} / d_{0}$, the gold recovery rate increases from $60.39 \%$ to $77.75 \%$ at the inlet pressure of $0.1 \mathrm{MPa}$. For the pressure of $0.15 \mathrm{MPa}$, it shows the same increasing tendency. At the condition that $\mathrm{d}_{\mathrm{s}} / \mathrm{d}_{\mathrm{o}}$ is 0.48 and feed pressure is $0.15 \mathrm{MPa}$, the separation effect is best and the recovery rate of gold in the underflow reaches to $78 \%$.

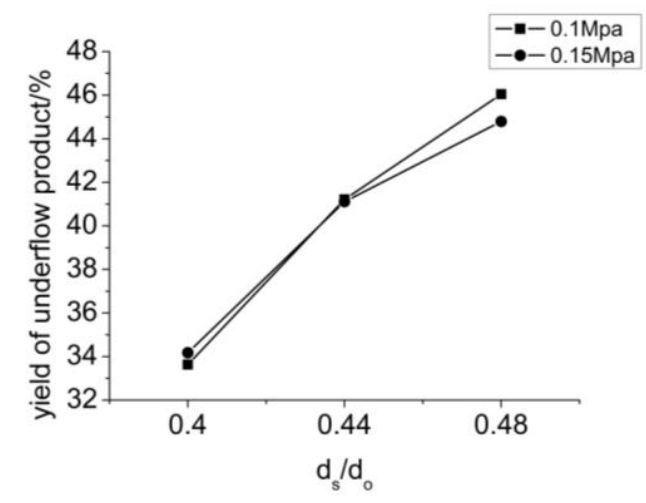

Figure 5. Yield of underflow product

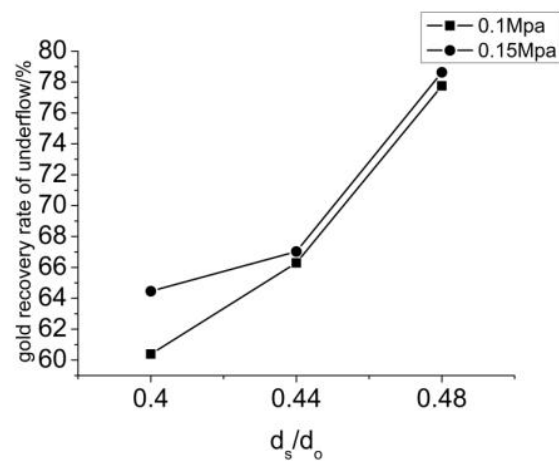

Figure 6. Gold recovery rate of underflow

\section{CONCLUSIONS}

The multi-conical hydrocyclone shows good desliming performance for the $-15 \mu \mathrm{m}$ particles of the gold tailing .It can reduce the gold grade of overflow and enrich that of the underflow. For the gold tailing with the gold grade of $0.45 \mathrm{~g} / \mathrm{t}$, the content of $-15 \mu \mathrm{m}$ size particles in the overflow can reach about $90 \%$, and in the underflow it is $10 \% \sim 17 \%$. Meanwhile, the gold grade of underflow increases to $0.75 \mathrm{~g} / \mathrm{t} \sim 0.8 \mathrm{~g} / \mathrm{t}$ after separation by the multi-conical hydrocyclone.

\section{ACKNOWLEDGEMENT}

The work is supported by the Key Laboratory of Gold Mineralization processes and Resource Utilization Subordinated to the Ministry of Land and Resources, Key Laboratory of Metallogenic Geological Process and Resources Utilization in Shandong Province (No.2013010).

\section{REFERENCES}

[1] M.Fall, M.Benzaazoua, S.Ouellet. 2005.Experimental characterization of the influence of tailings fineness and density on the quality of cemented paste backfill. Minerals Engineering 18(1):41-44.

[2] Ozgen.S. 2012. Modelling and optimization of clean chromite production from fine chromite tailings by a combination of multigravity separator and hydrocyclone. JOURNAL OF THE SOUTHERN AFRICAN INSTITUTE OF MINING AND METALLURGY 112(5):387-394.

[3] Da Li, Fang Qin Cheng, Jian Feng Li, Yun Shan Guan. 2013. A Numerical Study of Flow Field in a Hydrocyclone for Potash Ore Desliming. Applied Mechanics and Materials, Vol(448-453):3847-3850.

[4] D. O. Silva, L. G. M. Vieira, F. S. Lobato, M. A. S. Barrozo. 2012. Optimization of the design and performance of hydrocyclones by Differential Evolution technique. Chemical Engineering and Processing: Process Intensification Vol (61):1-7. 